Author Posting. (C) The Authors 2006. This is the author's version of the work. For full bibliographic citation, please refer to Appetite, 46, 67-74). http://dx.doi.org/ (DOI:10.1016/j.appet.2005.09.003).

\title{
Implicit attitudes towards Genetically Modified (GM) foods: A comparison of \\ context-free and context-dependent evaluations
}

\author{
Alexa Spence ${ }^{\mathrm{ab} *}$ and Ellen Townsend ${ }^{\mathrm{ab}}$ \\ ${ }^{a}$ School of Psychology, University of Nottingham, University Park, Nottingham, U.K. NG7 2RD. \\ ${ }^{b}$ Institute for the study of Genetics, Biorisks and Society, Law and Social Sciences Building, University of \\ Nottingham, University Park, Nottingham, U.K. NG7 2RD.
}

\footnotetext{
* Corresponding author.

E-mail address: 1pxas@psychology.nottingham.ac.uk (Alexa Spence)
} 


\begin{abstract}
$\underline{\text { Abstract }}$
Past research on attitudes towards GM food has focused on measuring explicit attitudes. Here we compared implicit attitudes towards GM foods with explicit attitudes towards GM foods. We used the Go No-Go task to investigate context-free implicit evaluations of GM foods and compared these with evaluations made in the context of ordinary and organic foods. Semantic differential scales were used to evaluate explicit attitudes towards GM foods. As expected, explicit attitudes towards GM foods were found to be neutral. However, contrary to our hypotheses, participants were found to hold positive, rather than neutral, implicit attitudes towards GM foods when these were assessed in a context free manner. In addition, neutral implicit attitudes were found when attitudes were assessed in the context of ordinary or organic foods, again contrasting with our hypotheses. These results imply that implicit attitudes towards GM food are more positive than anticipated and may lead to approach behaviour towards such products. Thus, given the choice, consumers are likely to accept GM food although other incentives may be needed if alternative foods are available.
\end{abstract}

Keywords: GM foods; Implicit attitudes; Explicit attitudes; Behaviour; Context 


\section{$\underline{\text { Introduction }}$}

Predicting the possible reactions of consumers to the introduction of GM foods is considered extremely important for a number of organisations including food producers and policy makers. Data relating to explicit attitudes towards GM foods is useful in predicting behaviour however implicit attitudes are also found to be independently useful in predicting behaviour (Fazio and Olson, 2003a). It is therefore important that implicit attitudes towards GM foods are evaluated in order to gain accurate predictions of behaviour. However, to date, no studies have attempted this. Although implicit attitudes are more consistent, and less flexible, than explicit attitudes they are susceptible to contextual influences. Thus, here we examined implicit evaluations of GM food, in the context of organic food and ordinary food as these are the likely alternatives for consumers.

\section{$\underline{\text { Explicit vs Implicit attitudes }}$}

Implicit attitudes differ from that of explicit attitude measurements in that responses measured are not consciously controlled; rather they are automatic or spontaneous. Various types of implicit attitude measures exist ranging from physiological measures, to examinations of non-verbal behaviour, to the more frequently used reaction time tasks (see Spence, 2005, for a review). In contrast, explicit attitude measures generally take the form of direct questions about how one feels about a particular topic. This means, of course that explicit attitude measures are open to self-presentation effects and demand characteristics.

The spontaneous nature of the measurement of implicit attitudes means that many of the external influences associated with measuring attitudes in an explicit 
manner are removed (as it is extremely difficult to control results on an implicit task (Steffens, 2004)) Moreover, implicit attitudes are more stable and less flexible than explicit attitudes and will only change over a longer period of time through a process of evaluative conditioning (Hermans, Baeyens and Eelen, 2003). Explicit attitudes, in contrast, appear to be easier to manipulate and can be altered in a short period of time as new information is received (Fazio and Olson, 2003b).

Although implicit attitudes are less flexible than explicit attitudes, they are still found to be susceptible to the influence of context effects. Framing the attitude object in different terms, or contrasting the attitude object with different categories, is likely to have an effect on implicit responses to that attitude object. For example, implicit attitudes towards liked Black athletes are found to be positive when their occupation is the focus of judgement, but negative when their race is the focus of judgement (Mitchell, Nosek and Banaji, 2003).

Although implicit attitudes towards GM foods have not previously been studied, implicit attitudes towards non-GM foods have been measured. The affective priming task was recently found to be useful in identifying both strong and moderate attitudes towards different food stimuli (Lamote, Hermans, Baeyens and Eelen, 2004). In addition, the Implicit Association Task (IAT) has been used to compare attitudes towards different foodstuffs. Maison, Greenwald and Bruin (2001) utilised the Implicit Association Task (IAT) to measure attitudes towards fruit juices and sodas and found that fruit juices were preferred to soda drinks, which mirrored explicit attitudes. The study concluded that the IAT was useful in assessing food attitudes. 


\section{$\underline{\text { Explicit attitudes towards GM foods }}$}

Most research on attitudes towards GM is survey-based, either in questionnaire or interview format (Frewer, Howard and Shepherd 1997; Wagner et. al. 1997; Gaskell et. al. 2000; Siegrist 2000; Cook, Kerr and Moore, 2002). The Eurobarometer series of studies is probably the largest investigation into explicit attitudes in Britain and across Europe. The most recent Eurobarometer report finds that the British population is ambivalent towards GM food (Gaskell, Allum and Stares, 2003; Gaskell, Allum, Bauer, Jackson, Howard and Lindsey, 2003). This finding is supported by the PABE (Public perceptions of Agricultural Biotechnologies in Europe) focus group study (Marris, Wynne, Simmons and Weldon, 2001) that indicated that a key finding was that participants expressed arguments both for and against GM foods. Attitudes towards GM foods are found to vary greatly across the EU and Britain seems to be firmly in the middle of the spectrum of opinion polls in its ambivalence. Countries such as Spain, Portugal, Ireland and Finland are all quite positive towards GM food whereas countries including France, Greece and Luxembourg are negative towards GM food (Gaskell, Allum and Stares, 2003). Differences in attitudes towards GM foods observed between countries are attributed to a variety of factors including culture, regulatory systems and local events including food scares.

A more recent poll, conducted in 2003, by the market research company MORI in conjunction with UEA (the University of East Anglia) again found that the majority of people in Britain were ambivalent towards GM foods (Poortinga and Pidgeon, 2004). However, their data was also found to be somewhat skewed so, of those individuals who are not ambivalent, more people think that GM food is a bad thing than think it is a good thing. It seems therefore, that although most people in Britain are ambivalent 
about GM foods, a large amount of people do have concerns about GM food. However, the reliability and validity of a number of these studies has recently been questioned (Townsend, Clarke and Travis, 2004, Campbell and Townsend, 2003).

\section{$\underline{\text { Relationship between explicit and implicit attitudes }}$}

The relationship between implicit and explicit attitudes is as yet unclear. Empirical examinations indicate that correlations between implicit and explicit attitudes are wide-ranging, correlating significantly in some domains but often having seemingly no relationship with one another. Low correlations are typically found within topics of high sensitivity, such as racial prejudice (Kawakami and Dovidio, 2001; Devine, Plant, Amodio, Harmon-Hones and Vance, 2002) indicating that this may be due to selfpresentation effects inherent within explicit measures.

In order to more clearly understand why differences between explicit and implicit attitudes may exist, their theoretical underpinnings require examination. Two main viewpoints exist to explain the relationship between implicit and explicit attitudes. The dominant viewpoint is the single attitude model (Smith and Decoster, 2000) which states that implicit and explicit attitudes are differing measures of the same attitudinal construct (and for this reason implicit attitudes should be referred to as implicit measures of attitudes). This model proposes that the differing measures actually measure differing processes that underpin the attitude construct. An alternative viewpoint is that implicit and explicit attitudes are distinct constructs and this is referred to as the model of dual attitudes (Wilson, Lindsey, and Schooler, 2000). The model of dual attitudes implies that an individual may hold two (or more) different evaluations of an attitude object at the same time and these can coexist without tension. Which 
attitude dominates will depend on whether an individual has the cognitive resources necessary to retrieve the explicit attitude. If s/he does this may then override the implicit attitude. No matter which theoretical stance is adhered to, it is clear that implicit and explicit attitudes often do not correlate.

\section{$\underline{\text { Predictive validity of implicit and explicit attitudes }}$}

Both explicit and implicit attitudes have been found to be important in the prediction of actual behaviour. It seems that deliberate, well thought out, behaviour is best predicted by explicit attitudes, whereas spontaneous behaviour is best predicted by implicit attitudes. For example, when examining food choice behaviour, it was found that explicit attitudes towards eating fruit and snacks were more predictive of self reported behaviour of the frequency of eating fruit and snacks than implicit attitudes (Perugini, 2005). Conversely, implicit attitudes towards fruit and snacks were found to be more predictive of a participant's spontaneous choice of either a fruit or a snack.

More recent research has focused on the likelihood that much behaviour may actually be made up of both implicit and explicit components, indicating that both implicit and explicit attitudes may be predictive of certain behaviours (Nosek, Banaji, and Greenwald, 2002; Perugini, 2005). This possibility may previously have been concealed because researchers have tended to use extreme forms of spontaneous or deliberate behaviour (e.g. Dovidio, Kawakami, Johnson, Johnson and Howard, 1997; Dovidio, Kawakami, and Gaertner, 2002; Neumann, Hulsenbeck and Seibt, 2004). A recent meta-analysis of the predictive value of the IAT found that behaviours such as brand-related choices and voting behaviour were better predicted by explicit attitudes but were also significantly predicted by implicit attitudes (Poehlman, Uhlmann, 
Greenwald and Banaji, Note 1). Thus, whilst implicit attitudes can best predict spontaneous behaviour, they may also predict more deliberate behaviours. However, the opposite was not found to be true for explicit attitudes which were found to be predictive only of deliberate behaviours and not spontaneous behaviour.

From the perspective of the single attitude model, it has been suggested that discordant explicit and implicit attitudes held towards a particular attitude object will result in internal conflict when determining behaviour (Epstein, 1994; Wilson et al, 2000). Supporting this idea, when correlations between implicit and explicit attitudes are low, predictive validity is found to be relatively worse for both measures (Poehlman, Uhlmann, Greenwald and Banaji, Note 1). This may occur because an individual may attempt to override an unwanted automatic response such that an explicit attitude has to overcome a given implicit attitude.

In correspondence with this, when correlations between implicit and explicit attitudes are high, predictive validity is enhanced although this has a greater influence on the accurate prediction of explicit attitudes than implicit attitudes. This may be due to the difficulties encountered in altering the influence of implicit attitudes as compared to explicit attitudes. More research is now needed into how implicit attitudes and explicit attitudes relate to each other and how these may combine in order to predict behaviour. It is clear that behaviour is better predicted by a combination of explicit attitudes and implicit attitudes than by explicit attitudes alone.

\section{Overview of study}

This study examined implicit attitudes towards GM foods and compared these with explicit attitudes held towards GM foods. A second aim was to examine how 
implicit attitudes towards GM foods, measured in a context free manner, compare to implicit attitudes towards GM foods measured in the context of (a) ordinary food and (b) organic food, as ecologically valid comparison categories. It was hypothesised that the context free version of the Go No-Go Association Task (GNAT) would reveal neutral attitudes towards GM foods. We predicted that the inclusion of the contexts of organic and ordinary food would result in the elicitation of negative implicit attitudes towards GM owing to a contrast with the positive implicit attitudes generally held towards normal foods and organic food types.

\section{$\underline{\text { Method }}$}

$\underline{\text { Design }}$

This study had a repeated measures design in which participants completed three different GNATs assessing implicit attitudes towards GM foods in different contexts ( $\mathrm{GM}$ alone vs. GM + ordinary food vs. GM + organic food). Each GNAT had two conditions, a positive one where responses were made in relation to 'pleasant' attribute words and a negative one with 'unpleasant' attribute words. Participants also completed an explicit attitude assessment of attitudes towards GM foods.

\section{Participants}

62 participants ( 25 males and 37 females) took part in the study; however, the data of 2 females were lost due to a computer error. Participants were recruited in a topic blind manner and all were university students with British citizenship. 


\section{$\underline{\text { Materials }}$}

\section{The GNAT}

The GNAT (Nosek and Banaji, 2001) is derived from the IAT (Greenwald, McGhee, and Schwartz, 1998) and is based on the same logic as other response competition tasks in that it is assumed that task performance will be superior when responses are to be made to a pair of strongly associated items, rather than a pair of weakly associated items. This task was chosen owing to its ability to compare context and context free associations with an attitude object.

The procedure of the GNAT requires that participants respond to certain categories (Go) and not to other categories (No-Go). In one part of the task, participants must respond to words belonging to the categories 'GM food' (e.g. 'engineered salmon' and 'modified tomatoes') and 'Pleasant' (e.g. 'like', 'happy' and 'excellent') and in a second part of the task participants must respond to words belonging to the categories 'GM food' and 'Unpleasant' (e.g. 'bad', 'horrible' and 'nasty'). Performance in the GNAT is analysed either by comparing the amount of errors made in each condition or by comparing reaction times in each condition. Here a comparison of reaction times was used as the internal consistency of the task is likely to be higher when using these (Nosek and Banaji, 2001). Responses must be made within a short response window of time; the window used in this experiment was 700ms. This was chosen as it is within the range $(500 \mathrm{~ms}-1000 \mathrm{~ms})$ examined by Nosek and Banaji (2001) in relation to response latency analysis in the GNAT; it is towards the lower end of the range as distinguishing GM food words is likely to be quite easy and because Nosek and Banaji (2001) found that effect sizes increase as the response window decreases. Participants are therefore presented with different word stimuli at a very fast pace and given only a 
short window of time within which they must process the word, decide which given category the word belongs to, and indicate their response by either hitting the space bar, or withholding a response.

In the context free version of the task the background to the target items (GM food) used was composed of pleasant or unpleasant attributes only. In one condition participants were required to respond to exemplars of the 'GM food' category and one set of attribute category words e.g. 'Pleasant' and to ignore exemplars of the opposing attribute category i.e. 'Unpleasant'. In a second condition, participants responded to the 'GM food' category and the other attribute category e.g. 'Unpleasant' and ignored the originally paired attribute category i.e. 'Pleasant'. In the contextualised conditions, the different contexts were created by adding other stimuli, related to the particular context required (e.g. organic foods or ordinary foods). These then form the background stimuli which the participant is not required to respond to. Here participants respond to exemplars of the GM food category and one attribute category, e.g. 'Pleasant', in one condition but this time they also have to ignore exemplars of the context category, e.g. 'Ordinary food', as well as exemplars of the opposing attribute category, i.e. 'Unpleasant'. The stimuli presented were exemplars of each category (GM food, Organic food and Ordinary food); five exemplar stimuli were used in each category, see Appendix 1. These were chosen as being easily recognisable instances of each category, in the same way as stimuli chosen within previous GNAT studies (Nosek and Banaji, 2001; Mitchell, Nosek and Banaji, 2003). This is because participants are found to make their responses to the category labels rather than to individual exemplars (De Houwer, 2001). Therefore results will represent associations with the categories (e.g. 
GM food, Organic food, Ordinary food) rather than an average of the actual exemplars used.

\section{Explicit attitudes}

Explicit attitudes were assessed using seven-point semantic differential scales, which are psychometrically robust and have been used to assess explicit attitudes towards GM food in past studies (e.g. Townsend, Clarke and Travis, 2004). Adjectives used to describe scale endpoints in the present study may be seen in Appendix 2. Explicit attitude was divided into its hypothesised components of affective, cognitive and evaluative parts for analysis. The items used were taken from Crites, Fabrigar \& Petty, (1994) whose scale has been used in much previous research (e.g. Giner-Sorolla, 2004; Huskinson and Haddock, 2004; Simons and Carey, 2000). The presentation of items was counterbalanced in terms of whether the positive item appeared on the left or the right hand side of the page.

\section{$\underline{\text { Procedure }}$}

Individuals were tested in a quiet room; each individual completed three GNATs and one explicit attitude questionnaire. Each section was presented to the participant individually and the instructions for each section were self-contained within the task. The implicit tasks were presented on a computer using E-Prime software and an experimenter was on hand to answer any questions. The order of the three GNAT tasks and the explicit attitude questionnaire was counterbalanced between participants to prevent order effects. Within each GNAT, there were two conditions; one in which the category of 'GM foods' was paired with the 'Pleasant' attribute category first and 
'Unpleasant' second. In the second condition this was reversed and the category of 'GM foods' was paired with the 'Unpleasant' attribute category words first and the 'Pleasant' words second. This was done in order to counteract overshadowing effects, which are practice effects associated with completing the first section that may slightly impede performance on the second section (Greenwald, McGhee and Schwartz, 1998). The two conditions of the GNAT were counterbalanced between participants. At the end of the experiment the aim of the study and the purpose of the methods were explained and any further questions were answered.

\section{$\underline{\text { Results }}$}

GNATs were analysed by comparing reaction times made between the different conditions within the task (see Table 1). In the context free GNAT, it was found that responses made to GM food words, when paired with positive words were significantly faster, at a mean speed of $490 \mathrm{ms,}$ than when paired with negative words, when responses were at a mean speed of 500ms. No differences were found between mean response times in the positive (pleasant words) and negative (unpleasant words) conditions for the GNAT that used the context of ordinary food. Neither were there any differences in response times in the GNAT that used the context of organic food. There were no order effects.

Insert Table 1 about here

With regard to explicit attitudes, GM food was rated on a scale from -3 to +3 for each of the items within each component (scales were reversed as necessary for analysis 
so that -3 indicated a totally negative evaluation and +3 indicated a completely positive evaluation). Internal consistencies were measured using Cronbach's alpha and the evaluative, cognitive and affective components displayed high consistencies of 0.95 , 0.88 and 0.81 respectively. The mean of these was then taken for each component and results suggest that each of these was neutral to positive (see Figure 1). The evaluative component showed a mean of 0.27 , the affective component showed a mean of 0.25 and the cognitive component showed a mean of 0.30 An overall explicit rating was also calculated by combining the three components; this had a mean of 0.27 and a one way t-test indicated that this was non significant $(t=1.902, p=n . s$.

Insert Figure 1 about here

Correlations were conducted between each of the GNAT tasks and the explicit measures (see Table 2). As several correlations were being conducted, Bonferroni corrections were used to ensure that results were not labelled significant erroneously. As 7 correlations were conducted, the significance level was required to be lower than $0.007(0.005 / 7)$ to be deemed significant. Correlations between the GNAT tasks and each of the explicit components, as well as the mean overall explicit rating, were all found to be non-significant. Correlations between the GNAT tasks were also found to be non-significant. Correlations between the affective, cognitive and evaluative components of the explicit attitude measure were significant. 


\section{$\underline{\text { Discussion }}$}

Overall we found that explicit evaluations of GM foods were neutral in valence. This supports results from previous research including the most recent Eurobarometer survey (Gaskell, Allum and Stares, 2003), and the PABE focus groups findings (Marris, Wynne, Simmons and Weldon, 2001), that indicate that the British population is generally ambivalent towards GM food.

Explicit and implicit evaluations of GM foods did not correlate significantly on any of the measures. This corresponds with previous research in socially sensitive areas (Kawakami and Dovidio, 2001; Devine, Plant, Amodio, Harmon-Hones and Vance, 2002) and the differences between measures are thought to be, at least partly, due to self presentation influences exerting an effect on explicit attitudes. The dual attitude model predicts that differences can be expected between implicit and explicit measures of attitude as these are conceptualised as distinct constructs which are formed in different ways. The low correlations between explicit and implicit attitudes towards GM foods found here have implications for the predictive value of these measures. Our results suggest that the predictive validity of these measures is likely to be lower for both of these constructs (especially for explicit attitudes), than if these were found to significantly correlate, as they may each drive behaviour in difference directions. This highlights the importance of using implicit attitudes when predicting potential behaviour towards GM foods.

The results of the GNATs indicate that implicit attitudes towards GM foods are positive when evaluated in a context free manner. Participants were recruited 'topic blind' and were all British citizens which suggests that our results are reflective (to a limited degree) of general implicit attitudes towards GM foods within students in 
Britain. However, the sample evaluated here is not a representative sample of the British population and therefore results cannot be generalised further than a student population. Interestingly, a number of studies have shown that those with higher socioeconomic status and higher education levels are likely to be more negative towards GM than other groups (e.g. Noussair et. al., 2004). So, given that our sample was drawn from a highly educated and prosperous population, to some extent this result is quite surprising. Future studies would benefit from recruiting community-based random samples in order to fully evaluate how the findings presented here may be generalised.

It was also found that implicit attitudes towards GM foods were neutral when evaluated in the context of ordinary food or organic food. This indicates that implicit attitudes towards GM foods may not be any different from implicit attitudes towards any other type of food. It is conceivable, therefore, that the positive implicit evaluation noted in the context free GNAT evaluating GM food actually measured a positive implicit evaluation that is held towards all food types. Nonetheless, GM foods seem to provoke a positive implicitly measured attitude, when measured in a context free manner, which has important implications for behaviour. In particular, more people than expected may purchase GM food if it becomes available in the UK.

As previously noted, behaviour is best predicted by a combination of implicit and explicit attitudes (Poehlman, Uhlmann, Greenwald and Banaji, Note 1). As explicit attitudes measured here were neutral, these do not predict either approach behaviour or avoidance behaviour with respect to GM food (though individually the cognitive component of explicit attitude toward GM food was significantly positive). Implicit attitudes, however, were positive when GM foods are measured in a context-free manner indicating that approach behaviour is likely towards GM foods. This now 
requires empirical confirmation, especially since we found neutral implicit attitudes towards GM foods when reactions to GM were measured against a context of ordinary or organic foods (indicating that individuals are equally likely to engage in approach or avoidance behaviour when encountering GM foods).

Recent evidence suggests that approach behaviour may be expected in consumer situations relating to GM foods. For example, Noussair et. al.(2004) discovered that most people are willing to accept GM at the right price. Moreover, several studies demonstrate a general willingness to taste GM products using a taste-test paradigm (Caporale and Monteleone, 2004; Townsend and Campbell, 2004; Lähteenmäki et. al., 2003). In practical terms, our results suggest that people in the U.K. are likely to try GM foods if they are given the choice. If this occurs against a background of other food alternatives, however, additional incentives may be required (such as cheaper price or nutritional benefits). Attitudes may also be affected by public communication campaigns and advertising about GM foods. Implicit attitudes will be influenced by repeated associations of GM foods with valent information whereas explicit attitudes will be influenced by information in a more considered way, in a cost - benefit type evaluation. Behaviour is likely to be driven by both of these attitudes types, although implicit attitudes are likely to have a greater influence on behaviour in more spontaneous situations and explicit attitudes are likely to dominate in more deliberate situations.

Future research should examine actual behaviour towards GM foods although this is difficult due to practical reasons in that it is not yet widely available in the UK. It would be particularly useful to explore the relationships between explicit attitude measures, implicit attitude measures, and actual behaviour towards GM foods. This 
would clarify the predictive validity of attitude measures as well as providing an insight into potential behaviour, and how this may change or be changed.

\section{$\underline{\text { Conclusions }}$}

In this first ever study to examine implicit attitudes toward GM food we found responses to be positive and this finding has important implications for behaviour. Our results suggest that positive implicitly measured attitudes may facilitate approach behaviour towards GM food particularly when a spontaneous choice is being made. Approach behaviour may be modified by explicit attitudes but the modulation will depend on whether the individual has the time and cognitive capacity with which to engage explicit processing. Given our finding that explicit attitudes towards GM foods were neutral to positive, we would expect that the behavioural outcome in this situation would be approach behaviour. However, behaviour may differ if GM foods are encountered in the context of other foods, and in this situation, our results suggest that approach and avoidance behaviour are equally likely to occur.

\section{$\underline{\text { Acknowledgements }}$}

This research was supported by an ESRC/NERC interdisciplinary post-graduate award and a Programme Grant awarded to IGBiS by the Leverhulme Trust. 


\section{References}

Campbell, S. and Townsend, E. (2003). Flaws undermine results of UK biotech debate. Nature. 425: 559.

Caporale, G. and Monteleone, E. (2004) Influence of information about manufacturing process on beer acceptability, Food Quality and Preference 15, 271-8.

Cook, A. J., Kerr, G. N., \& Moore, K. (2002). Attitudes and intentions towards purchasing GM food. Journal of Economic Psychology, 23, 557-572.

Crites, S. L., Fabrigar, L. R., \& Petty, R. E. (1994). Measuring the affective and cognitive properties of attitudes: Conceptual and methodological issues. Personality and Social Psychology Bulletin, 20, 619-634.

De Houwer, J. (2001). A structural and process analysis of the Implicit Association Test. Journal of Experimental Social Psychology. 37: 443-451.

Devine, P., Plant, E., Amodio, D., Harmon-Jones, E., Vance, S. (2002). The regulation of explicit and implicit race bias: the role of motivations to respond without prejudice. Journal of Personality and Social Psychology. 82: 835-848.

Dovidio, J., Kawakami, K., Johnson, C., Johnson, B. and Howard, A. (1997). On the nature of Prejudice: Automatic and Controlled Processes. Journal of Experimental Social Psychology. 33: 510-540. 
Dovidio, J. Kawakami, K. and Gaertner, S. (2002). Implicit and explicit prejudice and interracial interactions. Journal of Personality and Social Psychology. 82: 62-68.

Epstein, S. (1994). Integration of the cognitive and the psychodynamic unconscious. American Psychologist. 49: 709-724.

Fazio, R. H. and Olson, M. A. (2003a). Implicit measures in social cognition research: Their meaning and use. Annual review of Psychology. 54: 297-327.

Fazio, R. H., and Olson, M. A. (2003b). Attitudes: Foundations, functions, and consequences. In M. A. Hogg \& J. Cooper (Eds.), The Handbook of Social Psychology (pp. 139-160). London: Sage.

Frewer, L., Howard, C., \& Shepherd, R. (1997). Public concerns in the United Kingdom about general and specific applications of genetic engineering: Risk, benefit and ethics. Science Technology \& Human Values 22, 98-124.

Gaskell, G., Allum, N., Bauer, M., Durant, J., Allansdottir, A., Bonfadelli, H. et al. (2000). Biotechnology and the European public. Nature Biotechnology, 18, 935-938.

Gaskell, G., Allum, N., Bauer, M., Jackson, J., Howard, S., Lindsey, N. (2003). Ambivalent GM Nation? Public attitudes towards Biotechnology in the U.K., 19912002. Life sciences in European Society report. LSE. 
Gaskell, G., Allum, N., and Stares, S., (2003). Europeans and biotechnology in 2002: Eurobarometer 58.0.. Brussels: European Commission.

Giner-Sorolla, R. (2004). Is affective material in attitudes more accessible than cognitive material? The moderating role of attitude basis. European Journal of Social Psychology. 34: 761-780.

Greenwald, A., McGhee, D. and Schwartz, J. (1998). Measuring individual differences in implicit cognition: The implicit association test. Journal of Personality and Social Psychology. 74: $6:$ 1464-1480.

Hermans, D., Baeyens, F. and Eelen, P. (2003). On the Acquisition and Activation of Evaluative Information in Memory: The study of evaluative learning and affective priming combined. In J. Musch and D. C. Klauer (Eds.). The psychology of evaluation: Affective processes in cognition and emotion. NJ: Laurence Erlbaum.

Huskinson, T. L. H., and Haddock, G. (2004). Individual differences in attitude structure: Variance in the chronic reliance on affective and cognitive information. Journal of Experimental Social Psychology. 40: 1: 82-90.

Kawakami, K. and Dovidio, J. (2001). The reliability of implicit stereotyping? Or confronting prejudice: effects of prejudice labelling on stereotype activation. Personality and Social Psychology Bulletin. 27: 212-225. 
Lähteenmäki, L., Grunert, K., Ueland, Ø., Åström, A., Arvola, A., \& Bech-Larsen, T. (2003). Acceptability of genetically modified cheese presented as a real product alternative. Food Quality and Preference, 13, 523-533.

Lamote, S., Hermans, D., Baeyens, F, and Eelen, P. (2004). An exploration of affective priming as an indirect measure of food attitudes. Appetite. 42: 279-286.

Maison, D., Greenwald, A., and Bruin, R. (2001). The Implicit Association Test as a measure of implicit consumer attitudes. Polish Psychological Bulletin. 32: 61-69.

Marris, C., Wynne, B., Simmons, P. and Weldon, S. (2001). Public Perceptions of Agricultural Biotechnologies in Europe. PABE final report. Available at http://www.lancs.ac.uk/depts/ieppp/pabe/docs/pabe_finalreport.pdf

Mitchell, J. P., Nosek, B. and Banaji, M. (2003). Contextual variation in implicit evaluation. Journal of Experimental Psychology: General. 132: 3: 455-469.

Moon, W. and Balasubramanian (2001). Public Perceptions and Willingness-To-Pay a Premium for Non-GM Foods in the US and the UK. AgBioForum: 4: 3\&4: 221-231.

Neumann, R., Hulsenbeck, K. and Seibt, B. (2004). Attitudes towards people with AIDS and avoidance behaviour: Automatic and reflective bases of behaviour. Journal of Experimental Social Psychology. 40: 543-550. 
Nosek, B. A., and Banaji, M. R. (2001). The go/no-go association task. Social Cognition. 19: 625-666.

Nosek, B.A., Banaji, M.R., Greenwald, A.G. (2002). Math = male, me = female, therefore math $\neq$ me. Journal of Personality \& Social Psychology. 83. 44-59.

Noussair, C., Robin, S. and Ruffieux, B. (2004). Do consumers really refuse to buy genetically modified food? The Economic Journal. 114: 102-120.

Olson, M. A. and Fazio, R H. (2004). Reducing the Influence of Extrapersonal Associations on the Implicit Association Test: Personalizing the IAT. Journal of Personality and Social Psychology. 86: 5: 653-667.

Perugini, M. (2005). Predictive models of implicit and explicit attitudes. British Journal of Social Psychology. 44: 1: 29-45.

Poortinga, W. and Pidgeon, N. F. (2004). Public Perceptions of Genetically Modified Food and Crops, and the GM Nation? Public Debate on the Commercialisation of Agricultural Biotechnology in the UK (Understanding Risk Working Paper 04-01). Norwich: Centre for Environmental Risk.

Siegrist, M. (2000). The influence of trust and perceptions of risks and benefits on the acceptance of gene technology. Risk Analysis, 20, 195-203. 
Simons, J. and Carey, K. B. (2000). Attitudes toward marijuana use and drug-free experience: Relationships with behavior. Addictive Behaviors. 25: 3: 323-331.

Smith, E. R. and Decoster, J. (2000). Dual process models in social and cognitive psychology: Conceptual integration and links to underlying memory systems. Personality and Social Psychology Review. 4: 108-131.

Spence, A. (2005). Using implicit tasks in attitude research: A review and a guide. Social Psychological Review. 2-17.

Steffens, M. C. (2004). Is the Implicit Association Test Immune to Faking? Experimental Psychology. 51(x): 1-15.

Townsend, E. and Campbell, S. (2004). Psychological determinants of willingness to taste and purchase genetically modified food. Risk Analysis. 24: 1385-1393.

Townsend, E., Clarke, D. and Travis, B. (2004). Effects of Context and Feelings on Perceptions of Genetically Modified Food. Risk Analysis. 24: 5.

Wagner, W., Torgerson, H., Einsiedel, E., Jelsoe, E., Fredrickson, H., Lassen, J. et al. (1997). Europe ambivalent on biotechnology. Nature, 387, 845-847. 
Wilson, T. Lindsay, S. and Schooler, T (2000). A model of dual attitudes.

Psychological Review. 107 (1): 101-126. 


\section{$\underline{\text { Note } 1}$}

Poehlman, T., Uhlmann, E., Greenwald, A. and Banaji, M. (submitted). Understanding and using the Implicit Association Test: III. Meta-analysis of predictive validity.

Available at http://faculty.washington.edu/agg/unpublished.htm 
$\underline{\text { Appendix } 1 \text { - Stimuli used within GNATs }}$

\begin{tabular}{lllll} 
GM foods & Ordinary foods & Organic foods & Pleasant & Unpleasant \\
\hline Transgenic & Vegetables & Organic carrots & Excellent & Bad \\
crops & Sheep farming & Free range & Good & Horrible \\
GE livestock & Fruit farming & Unprocessed fruit & Happy & Nasty \\
GM plants & Haddock & Organic fish & Likeable & Dislike \\
Engineered & Potatoes & Natural ingredients & Wonderful & Terrible \\
salmon & & & & \\
Modified & & & & \\
tomatoes & & & &
\end{tabular}


Appendix $2-$ Semantic differential scales used to examine explicit attitudes

\begin{tabular}{|c|c|}
\hline Attitude component & Adjectives used \\
\hline Affective & $\begin{array}{l}\text { Love - Hateful } \\
\text { Delighted - Sad } \\
\text { Annoyed - Happy } \\
\text { Calm - Tense } \\
\text { Excited - Bored } \\
\text { Angry - Relaxed } \\
\text { Acceptance - Disgusted } \\
\text { Joy - Sorrow }\end{array}$ \\
\hline Cognitive & $\begin{array}{l}\text { Useful - Useless } \\
\text { Foolish - Wise } \\
\text { Unsafe - Safe } \\
\text { Harmful - Beneficial } \\
\text { Valuable - Worthless } \\
\text { Perfect - Imperfect } \\
\text { Unhealthy - Wholesome }\end{array}$ \\
\hline Evaluative & $\begin{array}{l}\text { Positive - Negative } \\
\text { Desirable - Undesirable } \\
\text { Bad - Good } \\
\text { Dislike - Like }\end{array}$ \\
\hline
\end{tabular}


Table 1 - Mean Reaction Times for each version of the GNATs

\begin{tabular}{|c|c|c|c|}
\hline Task & Mean (ms) & Standard & t-statistic \\
\hline
\end{tabular}

\section{Context free GNAT}

- 'GM food' and 'Pleasant'

490

33.7

$t=-3.76$

- 'GM food' and 'Unpleasant'

500

29.6

$(\mathrm{p}<0.001)$

GNAT with context of ordinary food

- 'GM food' and 'Pleasant'

509

34.4

$-0.78$

- 'GM food' and 'Unpleasant'

511

32.4

$(p=0.44)$

GNAT with context of organic food

- 'GM food' and 'Pleasant'

516

34.2

0.54

- 'GM food' and 'Unpleasant'

518

37.8

$(\mathrm{p}=0.59)$ 
$\underline{\text { Table } 2 \text { - Correlations between GNATs and explicit components }}$

GNATc GNATf GNATo Explicit - Explicit - Explicit - Overall Evaluative Cognitive Affective Explicit

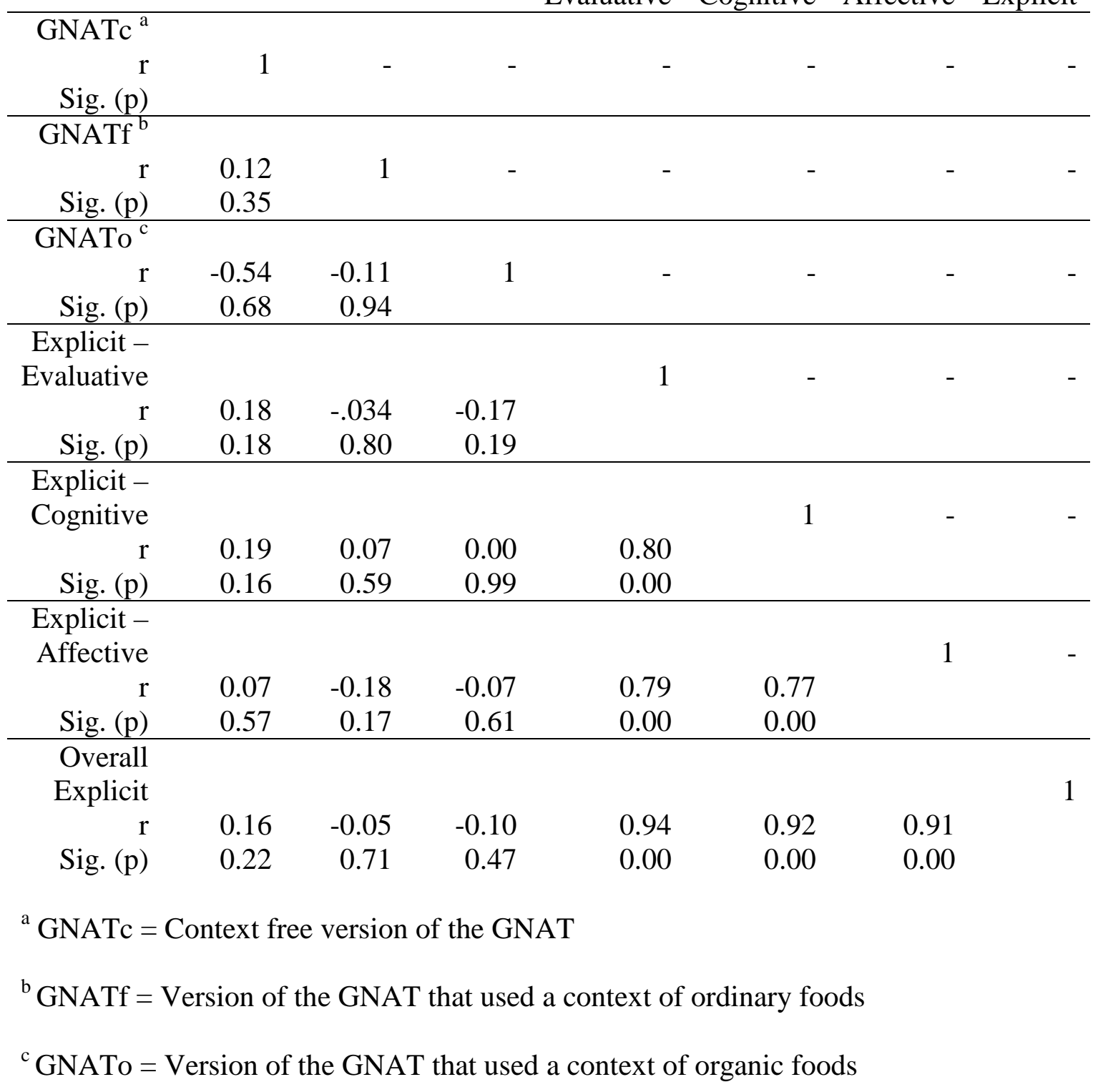




\section{Figure Captions}

Figure 1 - Mean explicit attitude component ratings are shown. One way t-tests indicated that the evaluative and the cognitive components were not significantly different from zero, $\mathrm{t}=1.49, \mathrm{p}=\mathrm{n} . \mathrm{s}$. , and $\mathrm{t}=1.80, \mathrm{p}=\mathrm{n}$.s. respectively, however the cognitive component was significantly different from zero, $\mathrm{t}=2.10, \mathrm{p}<0.05$. Standard deviations were 1.41, 1.08 and 1.09 for evaluative, affective and cognitive components respectively. 
$\underline{\text { Figure } 1 \text { - Mean explicit rating by component }}$

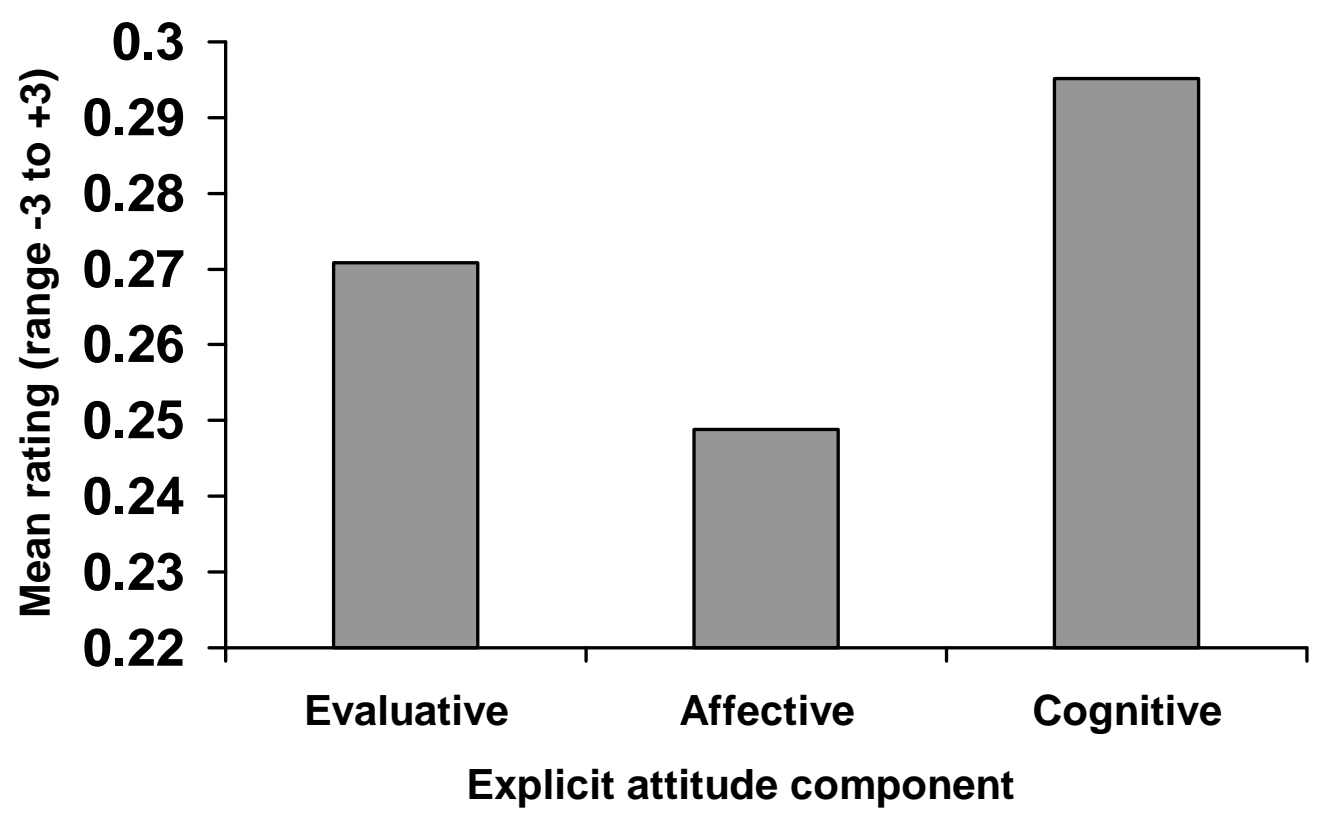

